\title{
REDUÇÃO DO IMPACTO FINANCEIRO E AMBIENTAL: ESTUDO DE CASO DA RECUPERAÇÃO DE UM EIXO DE ESCAVADEIRA HIDRÁULICA POR SOLDA SMAW.
}

\author{
Paulo Roberto Domingo da Silva ${ }^{1}$, Márcio Ramos da Silva ${ }^{2}$, João Vitor Rocha de Campos ${ }^{2}$ e \\ Paulo Roberto Cinti Ramos ${ }^{2}$, Anderson Elias Furtado ${ }^{2}$ \\ ${ }^{1}$ Tecno Steel Manutenção Industrial \\ ${ }^{2}$ FARO - Faculdade de Roseira. Engenharia Mecânica \\ E-mails: orcamento@tecnosteel-sp.com.br, marcio.silva11@gerdausummit.com, \\ joaovitor.campos@ faroroseira.edu.br, paulo.ramos@faroroseira.edu.br, \\ anderson.furtado@faroroseira.edu.br
}

\section{RESUMO}

A busca por menores impactos ambientais, somada à meta de redução de custos, vem alterando o paradigma das empresas: Reduzir o desperdício e o uso de matérias-primas devem receber maior atenção. Assim, novas tecnologias em relação às máquinas avançam com foco na satisfação do cliente, com melhoria no prazo de entrega e qualidade. Essas inovações tecnológicas acontecem de forma rápida e os processos de produção e manutenção, com recursos limitados, são obrigados a se adequar criando novos meios para manter o equipamento em boas condições de uso e com bom rendimento operacional. Os elementos de máquina recuperados podem ser uma opção para a manutenção com custos baixos e rapidez na entrega, permitindo redução no tempo de parada de máquina. Esse trabalho consiste na comparação entre recuperação por soldagem SMAW (arco elétrico com eletrodo revestido) e tratamentos térmicos ou a aquisição de um novo pino de articulação do braço secundário de uma escavadeira hidráulica Liebher 944, que apresentou desgaste e folga. Ao fim do estudo foi possível comprovar a viabilidade técnico-econômica da recuperação assegurando a funcionalidade do produto, menor custo, menor prazo de entrega e menor impacto ambiental já que o pino original não foi transformado em sucata, sendo mantido em operação.

\section{INTRODUÇÃO}

Apesar de recentemente o Brasil sofrer com uma queda na economia, ocorreu um aumento de $2,5 \%$ nas atividades do setor industrial e uma retomada de investimentos no ano de 2018 [1]. Com isso, a indústria necessita reconsiderar o planejamento de todos os setores, com grande enfoque às áreas de finanças e manutenção, revisando e alterando o necessário para suprir perdas e desenvolver novas soluções para práticas de aproveitamento e recuperação de elementos de máquina, de forma a minimizar os custos relacionados à manutenção. 
Nos processos industriais, há o desgaste de peças metálicas que implica na prática da manutenção de forma a garantir e otimizar a produtividade. A manutenção compõe-se de ações necessárias para que um item seja conservado ou recuperado de modo que permaneça com suas condições específicas [2]. A maneira como essas ações intervém nos equipamentos caracteriza o tipo de manutenção aplicada.

A atividade de manutenção tem passado por muitas alterações, devido ao aumento e complexidade de plantas e projetos com técnicas cada vez mais modernas, podendo ser classificada em três gerações, como indicado na Figura 1.

\begin{tabular}{|c|c|c|}
\hline $\begin{array}{c}\text { Primeira Geração } \\
\text { (Antes de 1940) }\end{array}$ & $\begin{array}{c}\text { Segunda Geração } \\
\quad(1940-1970)\end{array}$ & $\begin{array}{c}\text { Terceira Geração } \\
\text { (Após 1970) }\end{array}$ \\
\hline $\begin{array}{l}\text { - Conserto após } \\
\text { a falha }\end{array}$ & $\begin{array}{l}\text { - Computadores } \\
\text { grandes e lentos } \\
\text { - Sistemas manuais } \\
\text { de planejamento e } \\
\text { controle do trabalho } \\
\text { - Monitoração por } \\
\text { tempo }\end{array}$ & $\begin{array}{l}\text { - Monitoração de } \\
\text { condição } \\
\text { - } \text { Projetos voltados } \\
\text { para confiabilidade e } \\
\text { manutenibilidade } \\
\text { - Análise de risco } \\
\text { - Computadores } \\
\text { - } \text { pequenos e rápidos } \\
\text { - Análise de modos e } \\
\text { efeitos de falha } \\
\text { (FMEA) } \\
\text { - Grupos de trabalho } \\
\text { multidisciplinares }\end{array}$ \\
\hline
\end{tabular}

Figura 1. Mudanças nas técnicas de manutenção ao longo do tempo. Fonte: Adaptado de [3].

De acordo com a análise feita por Kardec e Nascif, considerando a manutenção corretiva não planejada, a preventiva e a preditiva/corretiva planejada, o custo da corretiva não planejada corresponde ao dobro da corretiva planejada, como pode se observar na Figura 2, na qual o custo está expresso em US\$ por HP por ano; sendo HP a potência instalada [3].

\begin{tabular}{cc}
\hline Tipos de Manutenção & Custo US\$/HP/ano \\
\hline Corretiva não planejada & 17 a 18 \\
Preventiva & 11 a 13 \\
Preditiva/Corretiva Planejada & 7 a 9 \\
\hline
\end{tabular}

Figura 2. Comparativo entre os custos dos diferentes tipos de manutenção industrial. Fonte: Adaptado de [3]. 
Dentre os diversos elementos de máquina que integram os equipamentos, o eixo que é foco deste projeto, é um elemento fundamental na articulação de máquinas e transmissão de potência por meio de rotação, e constantemente tem o seu funcionamento prejudicado por sofrer esforços demasiados ocasionando perdas e até mesmo a quebra do elemento [4]. Visando a economia de tempo e dinheiro relacionados à manutenção, é possível adquirir formas de recuperação em elementos de máquina, com rapidez, assegurando a mesma qualidade estrutural da original e com preços mais acessíveis, como é o caso da recuperação por soldagem.

A soldagem de manutenção recupera os componentes que sofreram esforços excessivos ou desgaste, além de reduzir custos e garantir a qualidade [5]. Pode ser aplicada para recuperar diversos equipamentos produzidos de diferentes materiais como aço, aço inox e ferro fundido. Os custos são relativamente baixos e são executadas de forma rápida e com garantia. A empresa especializada nesse método de recuperação deve possuir equipes totalmente qualificadas [6]. E é importante levar em consideração algumas características, tais como material e geometria da peça, acabamento superficial e dimensões, e materiais e equipamentos de soldagem [5].

Esse artigo busca comprovar a viabilidade técnico-econômica da recuperação assegurando a funcionalidade do produto, menor custo, menor prazo de entrega e menor impacto ambiental em comparação à compra de um novo eixo. Para tanto, esse artigo está dividido, além dessa introdução em mais 5 itens: o primeiro descrevendo em mais detalhes o processo de manutenção e recuperação de componentes por soldagem a arco elétrico. A seguir, uma descrição do componente a ser recuperado estudado nesse trabalho. No terceiro item os materiais, métodos e processos utilizados. O capítulo 4 é onde se apresentam os resultados e ele é seguido pelas conclusões.

\section{RECUPERAÇÃO POR SOLDAGEM A ARCO ELÉTRICO COM ELETRODO REVESTIDO - SMAW}

A recuperação por soldagem segue etapas pré-definidas padronizando modos de análise que permitam aplicar os métodos mais adequados de manutenção, que garantam a qualidade da peça. Primeiramente, deve-se analisar a falha: o local, a causa, o funcionamento, o reconhecimento dos materiais envolvidos e a determinação do estado do material. Então, define-se o processo de soldagem a ser aplicado, e em seguida a execução dos métodos: préusinagem, deformação, soldagem, pré e pós-aquecimento, tratamento térmico e pós-usinagem [7].

Na figura 3, a seguir, pode-se visualizar uma representação esquemática dessa sequência dessas atividades. 


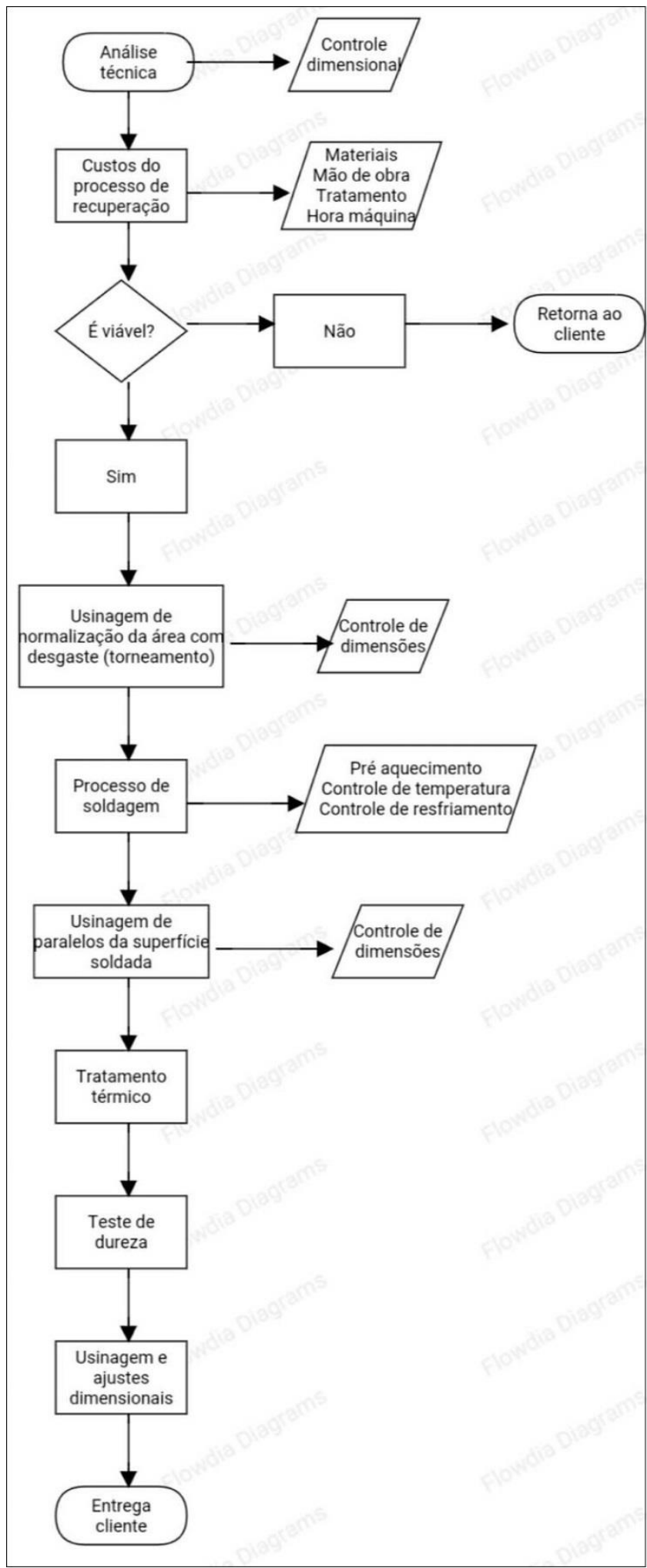

Figura 3. Fluxograma das etapas para realização de uma recuperação por soldagem. Fonte: Autores 
A soldagem a arco elétrico com eletrodo revestido é um processo de soldagem por fusão, sendo caracterizado pela fonte de energia utilizada: nesse caso, o arco elétrico que é uma descarga elétrica em um meio gasoso parcialmente ionizado. $\mathrm{O}$ arco elétrico é mantido entre um eletrodo, o metal-base. $\mathrm{O}$ eletrodo fundido pelo arco fornece metal de adição. $\mathrm{O}$ calor fornecido na soldagem, e as dimensões e formato do cordão de solda dependem diretamente da corrente e tensão elétricas fornecidas, e também da velocidade de soldagem. Na junta soldada, pode-se observar quatro regiões [8]:

$\checkmark$ Zona fundida (ZF): onde o material fundiu-se e solidificou-se com temperaturas superiores à de fusão do metal soldado;

$\checkmark$ Zona de fusão (ZF): com a combinação de características físicas, químicas e mecânicas dos materiais;

$\checkmark$ Zona termicamente afetada (ZTA): que é a zona afetada pelas altas temperaturas devido a transferência de calor, as quais provocam mudanças na estrutura do metal-base e nas propriedades mecânicas nessa região;

$\checkmark$ Metal-base: o qual não é atingido pelo processo de soldagem por ser mais afastado

Devido às altas faixas de temperaturas a que são submetidas às peças soldadas, existem mecanismos para evitar o aparecimento de trincas, como a seleção correta do consumível, o pré-aquecimento e pós-aquecimento da peça.

A representação gráfica dessas quatro regiões pode ser vista na Figura 4, a seguir.

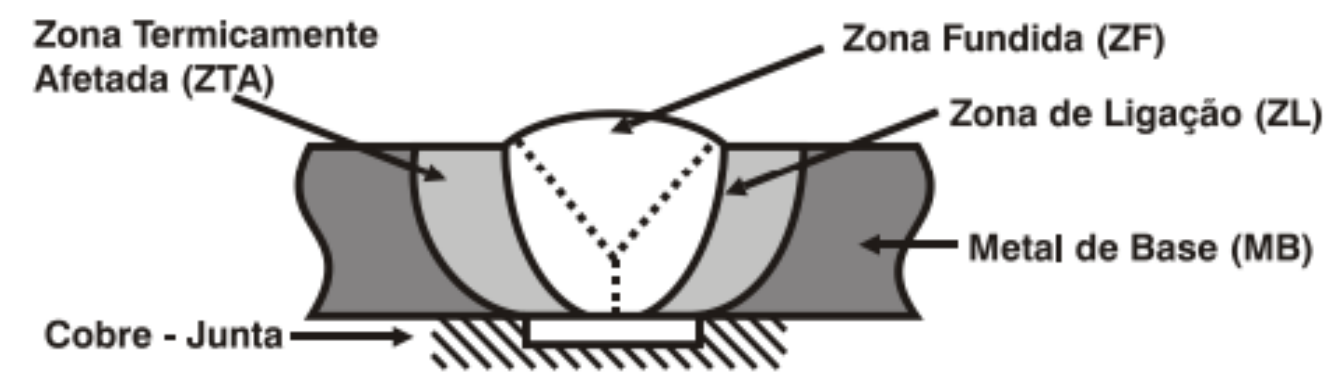

Figura 4. Regiões presentes numa junta soldada. Fonte: [8]

A Soldagem a Arco com Eletrodos Revestidos (SMAW), utiliza um eletrodo revestido, onde o núcleo (chamado alma) possui entre 250 a $500 \mathrm{~mm}$ de comprimento e conduz a corrente elétrica servindo como metal de adição, podendo conter elementos para influenciar as características metalúrgicas. O eletrodo é revestido com camadas de minerais e outros materiais com diâmetros variando entre 2 a $8 \mathrm{~mm}$. Esse revestimento estabiliza o arco e gera escórias que protegem a região soldada contra a ação da atmosfera [9].

Desta forma, existe uma grande variedade de eletrodos revestidos, cada qual com um tipo de revestimento com a capacidade de produzir gases mais adequados a cada tipo de aplicação. Os revestimentos dos eletrodos são caracterizados de acordo com a sua composição: oxidante, ácido, rutílico, celulósico e básico [10]. 
Os oxidantes são compostos basicamente de óxido de ferro e manganês, produzindo escória em abundância e fácil de destacar, e o cordão tem boa aparência. A evolução dos oxidantes com adição de sílica resultou nos revestimentos ácidos, permitindo um cordão de boa aparência, porém, poroso. Os rutílicos são fabricados com areia de rutilo (óxido de titânio) ou ilmenita (óxido de ferro e titânio) e proporcionam alta estabilidade do arco uma escória densa e fácil de destacar. Com grande quantidade de materiais orgânicos, especialmente celulose, os celulósicos formam uma escoria fina e de rápida solidificação. A penetração do cordão é alta, porém o volume de respingos é alto e isso confere uma aparência ruim ao cordão [11].

O revestimento mais adequado para soldar aços-liga, é o básico, devido à baixa tendência em oxidar metais. Seu cordão tem penetração média e requer secagem [11]. O processo de soldagem SMAW e o eletrodo revestido estão representados na Figura 5, a seguir.

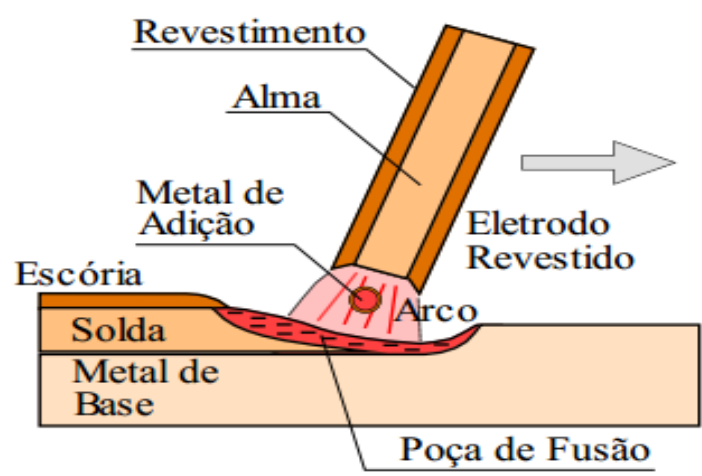

Figura 5. O processo de solda a arco com eletrodo revestido. Fonte: [9]

\section{O COMPONENTE A SER RECUPERADO}

As escavadeiras hidráulicas são equipamentos que recebem constantemente grandes esforços em suas estruturas, elementos hidráulicos e articulações. Na sua estrutura possuem eixos de fixação e articulação como o da Figura 6, que sofrem grandes esforços mecânicos, sendo eles de fricção, torção e compressão. Desta forma, tratam-se de eixos que devem possuir alta resistência mecânica, sendo fabricados com aços ARBL e subsequente tratamento térmico.

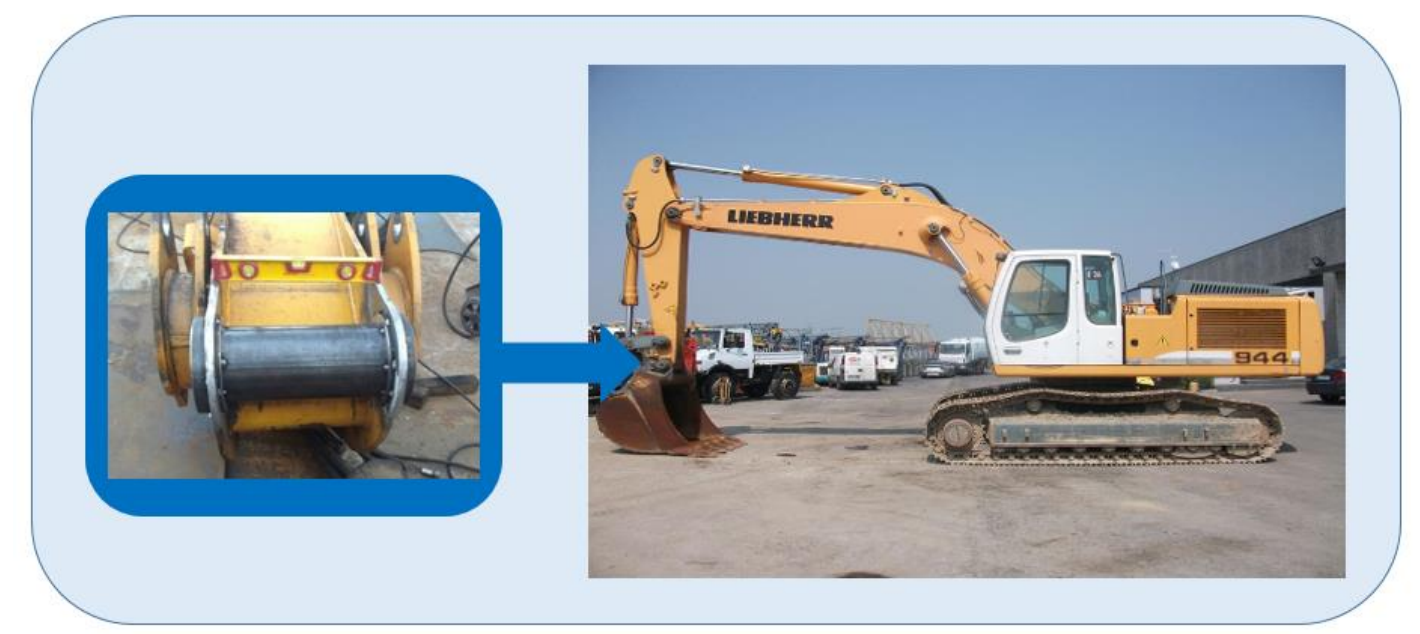

Figura 6. Eixo da articulação da concha analisado nesse trabalho e sua localização na escavadeira R944C. Fonte: Adaptado de [12]. 
No caso deste projeto o eixo da Escavadeira Hidráulica Liebherr 944C de uma empresa do Vale do Paraíba em São Paulo apresentava folgas excessivas na articulação da concha devido ao desgaste e precisava ser recuperado ou trocado.

Esse eixo é produzido de um aço SAE 4340, tratando-se, portanto, de um aço ARBL com liga níquel, cromo e molibdênio com composição química aproximada de $0,4 \%$ de Carbono, $1,82 \%$ de $\mathrm{Ni}$, o $\mathrm{Cr}$ variando entre 0,50 e $0,80 \%$ e o Mo em 0,25\%, além dos elementos silício e manganês. As dimensões do componente podem ser vistas na Figura 7, abaixo.

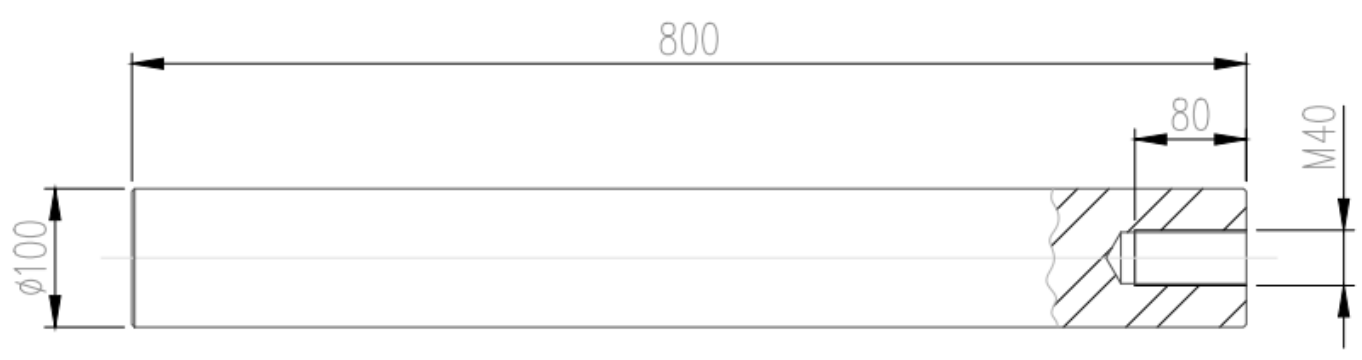

Figura 7. Dimensões do eixo a recuperar de projeto do eixo a recuperar.

Fonte: Autores

\section{MATERIAIS E MÉTODOS}

Ao receber a solicitação do trabalho, para confecção do orçamento e plano de recuperação, inicialmente buscou-se - conforme citado no capítulo anterior - conhecer as características dimensionais e propriedades mecânicas do material constitutivo do eixo, conforme suas especificações de projeto.

A seguir, o eixo foi desmontado do veículo e analisada sua condição dimensional real. Assim, definida a região desgastada, optou-se por realização de um desbaste uniforme na área impactada de forma a que a solda posterior pudesse ser a mais homogênea e controlada possível. O resultado dessa análise pode ser visto na Figura 8, a seguir.
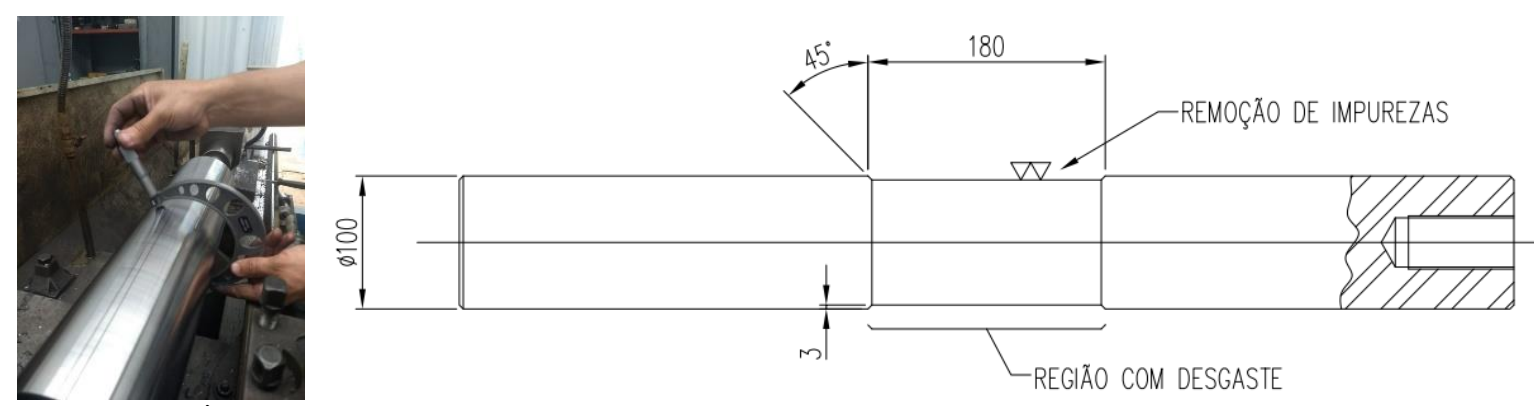

Figura 8. À esquerda, análise e dimensionamento do eixo conforme retirado da escavadeira e à direita - após identificação da área desgastada - proposta de área de desbaste para recuperação por soldagem SMAW do componente.

Fonte: Autores

Por se tratar de eixo em aço microligado SAE 4340 com superfície temperada e revenida o mesmo apresenta nesse estado baixa usinabilidade, sendo assim a primeira etapa para a 
recuperação do eixo foi realizado o tratamento de normalização do mesmo, para diminuir a elevada dureza da estrutura matensitica para uma estrutura composta por (perlita fina, ferrita,...) desfazendo assim a camada superficial temperada e revenida.

Com o eixo normalizado, passou-se à etapa de usinagem por torneamento da zona desgastada, conforme o desenho já apresentado na Figura 8, anteriormente.

Após essas etapas de preparação, passa-se à recuperação propriamente dita do eixo. Devido ao baixo custo, acessibilidade, versatilidade e extensa gama de ligas especiais, o processo de soldagem a arco elétrico com eletrodo revestido - SMAW (Shielded Metal Arc Welding) foi adotado para recuperação do elemento. Antes da solda a região desbastada sofreu um préaquecimento de $370^{\circ} \mathrm{C}$, o qual é recomendado para os aços Cromo/Níquel/Molibdênio segundo tabela de pré-aquecimento fornecida pela empresa EUTECTIC CASTOLIN (conforme figura 9, a seguir). A solda foi realizada com o eletrodo EUTECTRODE N 12 CGS 3,2 e com um controle de interpasses de $280^{\circ} \mathrm{C}$ a $250^{\circ} \mathrm{C}$, com passe de altura de deposição de $+/-2,5 \mathrm{~mm}$ e após outro passe para retirada de concavidades, entre passes.

\begin{tabular}{cc}
\hline Porcentagem de Carbono & Faixa de Temperatura \\
\hline Até $0,25 \%$ & Não requer pré-aquecimento \\
De $0,25 \%$ até $0,45 \%$ & $100^{\circ}$ a $200^{\circ} \mathrm{C}$ \\
De $0,45 \%$ até $0,80 \%$ & $200^{\circ}$ a $300^{\circ} \mathrm{C}$ \\
\hline
\end{tabular}

Figura 9. Faixas de temperaturas de pré-aquecimento indicadas pelo fornecedor do eletrodo utilizado na recuperação do eixo. Fonte: [8]

A fim de assegurar a uniformidade de propriedades e a usinabilidade do componente final, após a soldagem, o elemento (eixo) foi isolado por uma manta térmica para que obtivesse um resfriamento lento, minimizando a possibilidade de trincas causadas pelo efeito do choque térmico e o endurecimento precoce, que dificultariam a aplicação do processo de usinagem.

Após o resfriamento total até a temperatura ambiente, o eixo foi desbastado na superfície irregular na área soldada. Durante o torneamento de acabamento medições foram feitas garantindo assim as dimensões e tolerâncias do componente conforme seu projeto original.

Após a usinagem, o eixo foi submetido a um tratamento térmico para elevação da dureza e consequentemente o aumento da resistência mecânica. No processo da têmpera, o aquecimento é superior à temperatura crítica, que é de $727^{\circ} \mathrm{C}$, podendo ser maior de acordo com a liga do aço, o objetivo foi realizar mudança de fase para melhorar a estrutura cristalina do aço. A temperatura de aquecimento utilizada nesse trabalho foi de $870^{\circ} \mathrm{C}$ e o resfriamento realizado em salmoura.

Ao fim do tratamento térmico foram realizadas verificações dimensionais do eixo acabado e medições de dureza HRC tanto da área soldada quanto do material de base a fim de assegurar a conformidade componente e o mesmo foi remontado na escavadeira e entregue ao solicitando do trabalho. 
Assim, em resumo, a recuperação do elemento foi realizada em etapas conforme o fluxograma apresentado na Figura 10, a seguir:

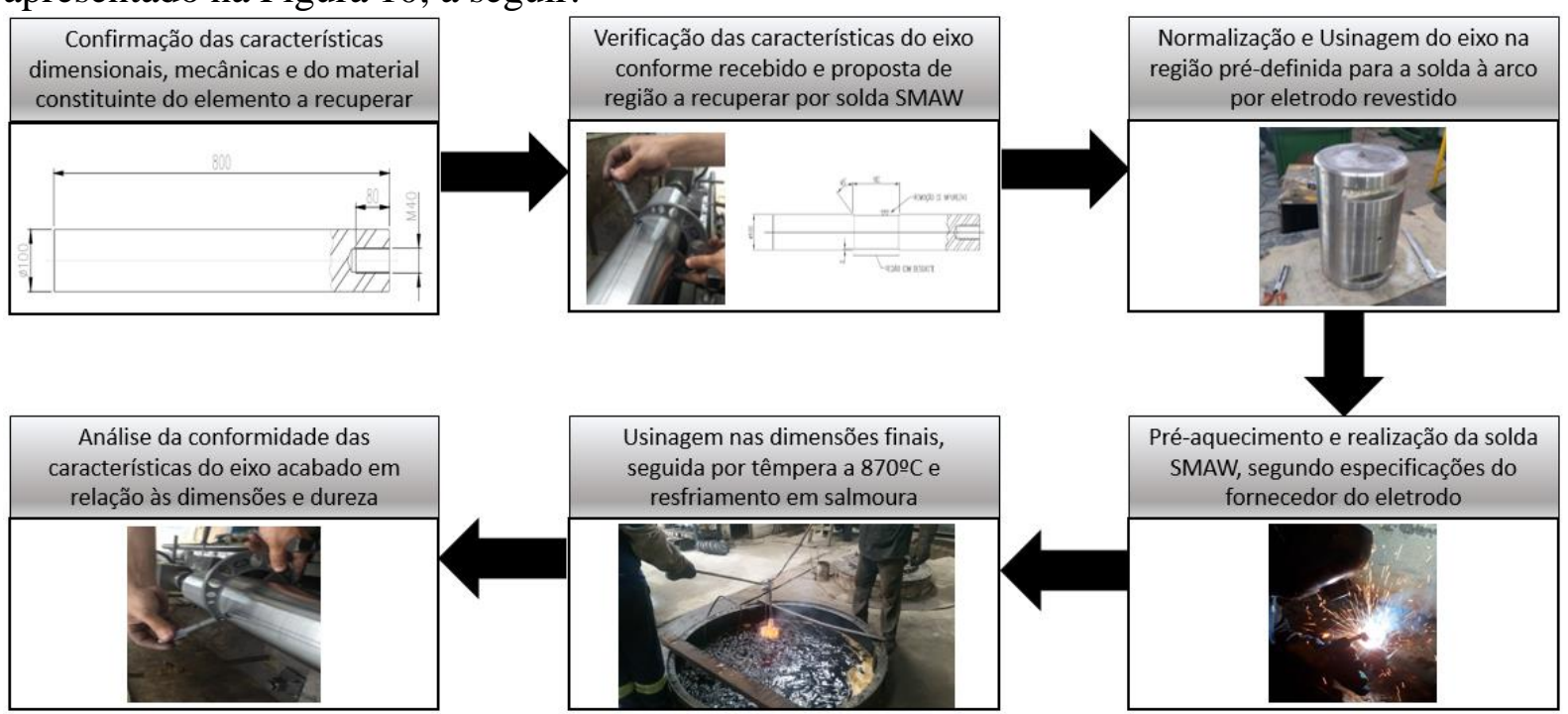

Figura 10. Etapas realizadas para análise e recuperação do eixo por solda SMAW.

Fonte: Autores

\section{RESULTADOS E ANÁLISES}

Após a finalização de todo o processo, e garantia de conformidade dimensional do eixo, para análise da conformidade do material foi realizada medição da dureza na zona recuperada por solda, sendo encontrado o valor de 55 HRC. Esse valor é similar ao especificado para o material de base (SAE 4340) temperado, o qual, de acordo com especificação do fornecedor Gerdau [13], deve ter dureza variando entre 54 e 55 HRC.

Em relação à análise de viabilidade econômica foram utilizados dados de mercado na data de janeiro de 2018 e obteve-se os seguintes resultados.

O custo com eletrodo foi de $\mathrm{R} \$ 477,18$, conforme pode ser visto na Figura 11, a seguir.

\begin{tabular}{|c|c|c|c|c|}
\hline \multicolumn{5}{|c|}{ Custo com consumíveis - Eletrodo para metais duros } \\
\hline Descrição & Quant. & Preço & IPI\% & Total \\
\hline EUTECTRODE N 12 CGS 3,2 & 5 & $\mathrm{R} \$ 86,76$ & 10 & $\mathrm{R} \$ 477,18$ \\
\hline \multicolumn{4}{|c|}{ Valor Total } & $\mathrm{R} \$ 477,18$ \\
\hline
\end{tabular}

Figura 11. Custo com consumíveis (eletrodos) utilizados na recuperação do eixo. Fonte: Autores

Além desse custo, foram inclusos no orçamento as despesas relativas aos processos de soldagem, usinagem, tratamento térmico e deslocamentos para execução de todas as etapas. Esses custos acrescidos ao dos consumíveis gerou uma fatura final no valor total de $\mathrm{R} \$ 1800,00$.

A fim de permitir um comparativo, também foi realizado o orçamento de um eixo novo e o valor médio de mercado foi de $\mathrm{R} \$ 4280,00$. 
Em relação aos prazos, o eixo novo teria prazo de entrega em 30 dias após o pedido e já o eixo retrabalhado pôde ser recolocado no equipamento 5 dias após o início dos trabalhos.

\section{CONCLUSÃO}

Analisando os resultados dimensionais, de características microestruturais e de dureza tanto da região recuperada por solda quando do material base em outras regiões do eixo, pode-se concluir que a recuperação atingiu seu objetivo em relação às propriedades mecânicas e que, portanto, o eixo pode ser novamente utilizado sem folgas e nem estará sujeito a desgastes excessivos no curto prazo.

Em relação aos custos envolvidos, uma simples comparação direta do valor para aquisição de um eixo novo, em torno de 4200 reais no valor médio de mercado em janeiro de 2018 com o custo da recuperação por solda SMAW, o qual foi de R \$1800,00, já permite identificar uma redução de quase $60 \%$ o custo para tornar novamente operacional a retroescavadeira.

Além disso, pode-se ainda somar ao ganho o valor de tempo de utilização de máquina: Como o processo de recuperação gerou cinco dias de máquina parada e a aquisição de um novo implicaria em trinta dias sem utilização do equipamento, bastaria multiplicar por 25 (diferença no número de dias de máquina parada para cada caso) o valor do trabalho realizado pela retroescavadeira por dia e teríamos o valor economizado a adicionar à economia já obtida pelo custo inferior de realização da recuperação.

Além desses fatores diretamente mensuráveis pela empresa proprietária da retroescavadeira, outra importante diferença é que ao utilizar apenas os eletrodos consumíveis e a eletricidade para os processos de usinagem, solda e tratamentos térmicos, deixou-se de fazer a fabricação e aquisição de outro eixo. Essa fabricação com toda certeza consumiria muito mais material (tratando-se de aço microligado com alguns elementos bastante raros que deixaram de ser consumidos) e energia na sua extração, beneficiamento e fabricação do eixo finalizado.

Sendo assim, fica a conclusão de que - nesse caso - o processo de recuperação por solda com eletrodo revestido, além de atingir totalmente a necessidade técnica, permite a manutenção do equipamento com um valor bastante inferior ao da aquisição de novo eixo e ainda é mais amigável com o meio ambiente por gerar economia na utilização de matéria prima e energia no processo de manutenção.

\section{REFERÊNCIAS}

[1] INSTITUTO BRASILEIRO DE GEOGRAFIA E ESTATÍSTICA. "Em fevereiro, produção industrial variou $0,2 \%$ ".

Disponível em https://agenciadenoticias.ibge.gov.br/agencia-sala-de-imprensa/2013-agenciade-noticias/releases/20710-em-fevereiro-producao-industrial-variou-0-2, 03 de abril de 2018. Acesso em maio de 2018.

[2] TAVARES, Lourival Augusto. “Controle de Manutenção por Computador”. Rio de Janeiro: Técnica, 1987. 
[3] KARDEC, Allan; NASCIF, Júlio. "Manutenção: Função estratégica". QualityMark editora, $4^{\text {a }}$ Edição, revista e ampliada. 2012.

[4] ESSEL: "Curso profissionalizante online - Manutenção. Aula 22. Eixos e Correntes." Disponível em http://essel.com.br/cursos/material/01/Manutencao/22manu2.pdf. Acesso em agosto 2018.

[5] PERTICARARI TESTING - ENGENHARIA DE INSPEÇÃO INDUSTRIAL. "Recondicionamento por soldagem".

Disponível em http://www.perticararitesting.com.br/perti.asp?menu=3\&codigo=13. Acesso em março de 2018.

[6] WELD - Soluções em Soldagem. "Recuperação por soldagem". Disponível em http://www.weld.com.br/recuperacao-soldagem. Acesso em maio de 2018.

[7] SERVIÇO NACIONAL DE APRENDIZADO INDUSTRIAL. "Noções Básicas de Processos de Soldagem e Corte". SENAI-ES, 1996. 123p.

[8] EUTECTIC CASTOLIN. "Manual de Aplicações de Soldagem: catálogo”. Março, 2017. 337p.

[9] MARQUES, Paulo Villani; MODENESI, Paulo José; BRACARENSE, Alexandre Queiroz. "SOLDAGEM: Fundamento e Tecnologia". Belo Horizonte: UFMG, 2011. 363 p.

[10] BRASIL ELEKTRISKA SVETSNINGS AKTIE BOLAGET. “Eletrodos Revestidos”. Disponível em:

http://www.esab.com.br/br/pt/education/apostilas/upload/1901097rev1_apostilaeletrodosreves tidos_ok.pdf. 2005. Acesso em agosto de 2018.

[11] BALMER. "Processo de Soldagem ao Arco Elétrico: Eletrodo Revestido". Disponível em www.balmer.com.br/balmer/wp.../12/Balmer-Treinamento-EletrodoRevestido.pdff. Acesso em abril de 2018.

[12] BRB spa. "LIEBHERR R944C HDS Litronic". Disponível em:

https://www.brbspa.it/en/liebherr-r944c-hds-litronic. Acesso em maio de 2019.

[13] GUERDAU. “Aços Longos Especiais: Gerdau 4340”. Disponível em:

https://www.gerdau.com/pt/produtos/gerdau-4340\#ad-image-0. Acesso em agosto de 2018. 